\title{
Genetic parameters for serial, automatically recorded milkability and its relationship to udder health in dairy cattle
}

\author{
S. Gäde ${ }^{\dagger}$, E. Stamer, J. Bennewitz, W. Junge and E. Kalm \\ Institute of Animal Breeding and Husbandry, Christian-Albrechts-University, Hermann-RodewaldStraße 6, D-24118 Kiel, Germany
}

(Received 31 October 2006; Accepted 29 March 2007)

\begin{abstract}
Serial measurements of three milkability traits from two commercial dairy farms in Germany were used to estimate heritabilities and breeding values (BVs). Overall, 6352 cows in first, second and third lactations supplied 2188810 records based on daily values recorded from 1998 to 2003. Only the records between day 8 and day 305 after calving were considered. The estimated genetic correlations between different parities within the three milkability traits ranged from $\mathrm{r}_{g}=0.88$ to 0.98 , i.e. they were sufficiently high to warrant a repeatability model. The resulting estimated heritability coefficients were $\mathrm{h}^{2}=0.42$ for average milk flow, $\mathrm{h}^{2}=0.56$ for maximum milk flow and $\mathrm{h}^{2}=0.38$ for milking time. We analysed the genetic correlation between milkability and somatic cell score (SCS) and between milkability and the liability to mastitis, respectively, as the optimum milk flow for udder health is not well defined. There were 66146 records with information on somatic cell count. Furthermore, 23488 days of medical treatment for udder diseases were available, resulting in 2600302 days of observation in total. Heritabilities for the liability to mastitis, estimated with a test-day threshold model, were $\mathrm{h}^{2}=0.19$ and $\mathrm{h}^{2}=0.13$, depending on the data-recording period (first 50 days of lactation and first 305 days of lactation, respectively). With respect to the relationship between milkability and udder health, the results indicated a slight and linear correlation insofar as one can assume: the higher the milk flow, the worse the udder health. For this reason, bulls and cows with high BVs for milk flow should be excluded from breeding to avoid a deterioration of udder health. The establishment of a special data-recording scheme for functional traits such as milkability and mastitis on commercial dairy farms may be possible according to these results.
\end{abstract}

Keywords: genetic parameters, mastitis, milkability, serial data, threshold model

\section{Introduction}

Although production traits are of primary economic importance, functional, cost-saving traits such as milkability and udder health are of increasing interest to producers to improve herd profitability (Groen et al., 1997). At the same time, the database for functional traits is currently scarce (Rensing, 2005). One of the functional traits, milkability, is of interest because of the interrelation to both labour efficiency and udder health (Pérez-Guzmán, 1984; Göft et al., 1994). Increased milk flow and decreased milking time, respectively, mean a decrease in labour required for milking, and labour accounts for a large fraction of the total cost of milk production (Lind, 2006). Lind (2006) calculated a mean economic value for milkability of 2.42 Euro per genetic standard deviation in German Holsteins. But a higher milk flow is also associated with an increase in problems in

\footnotetext{
${ }^{\dagger}$ E-mail: sgaede@tierzucht.uni-kiel.de
}

terms of udder health (Grindal and Hillerton, 1991; Boettcher et al., 1998; Zwald et al., 2005). However, during selection on milkability the known relationship to udder health is often disregarded. The relationship between milkability and udder health is comprehensible because both trait complexes are linked to the anatomy of the teat canal. Animals with a wider teat canal and sphincter on average show a higher milk flow, but teat canals with a greater diameter simultaneously facilitate access by pathogens (Persson Waller et al., 2003). Other studies have shown indications of the existence of a non-linear relationship between milking speed and udder diseases, insofar as a medium milk flow is optimal with respect to susceptibility to mastitis (Luttinen and Juga, 1997; Roth et al., 1998; Zwald et al., 2005). An increased incidence of mastitis in slow-milking cows could be due to incomplete milk-out or irritated teat ends because of extended milking time. Thus, pooling the results of the literature, milkability may have an intermediate optimum, because cows that 
milk too slowly will disrupt parlour flow and reduce milking efficiency, but cows that milk too quickly may be at a higher risk for mastitis.

Milkability is sufficiently heritable so as to make selective breeding sensible. In the literature, heritabilities range from $h^{2}=0.21$ to $h^{2}=0.36$ for average milk flow, from $h^{2}=0.21$ to $h^{2}=0.48$ for maximum milk flow, from $h^{2}=0.16$ to $h^{2}=0.35$ for milking time and from $h^{2}=0.15$ to $h^{2}=0.24$ for subjectively scored milkability (Trede, 1987; Göft et al., 1994; Bahr et al., 1995; Duda, 1995; Luttinen and Juga, 1997; Boettcher et al., 1998; Santus and Bagnato, 1998; Rupp and Boichard, 1999). Interpreting the genetic parameters from the literature, it is worth noting that the data obtained for the respective estimations consisted of singular measurements, i.e. the milkability was recorded only once per animal and moreover, often subjectively.

In contrast, today some farms offer the possibility of automatic recording of milk yield and thus provide serial data on milkability traits such as milk flow and milking time. Therefore, an uninterrupted milkability test over the course of lactation is possible, meaning that there is information concerning every day and every parity. In previous studies, heritabilities were estimated for milkability traits based on serial data ranging from $h^{2}=0.003$ to $h^{2}=0.55$ (Zwald et al., 2005; Gäde et al., 2006; Karacaören et al., 2006).

The objective of this study was to examine the possibility of using serial, automatically recorded milkability data from commercial dairy farms for performance tests and subsequent selection. Thus, estimations of variance components and breeding values (BVs) were carried out using data from two commercial dairy farms as an example. Three milkability traits were evaluated. These were the average milk flow rate, the maximum milk flow rate and the milking time. A further objective was to assess the genetic correlation between serially recorded milkability and udder health traits such as monthly recorded somatic cell count (SCC) and daily recorded mastitis to help define the optimum range for milkability.

\section{Material and methods}

\section{Data}

Data were recorded on two large commercial dairy farms with an overall number of 2000 milking German Holstein cows. The farms were involved in a project to develop a new data-recording scheme, with special focus on the recording of functional traits. Data were collected from February 1998 until September 2002 (farm 1) and from February 1998 until December 2003 (farm 2), respectively.

Summarising the number of all dairy cows which provided the data over the years of recording, there were 6352 cows from 476 sires (Table 1); that is, an average of 13.3 daughters per sire. About $50 \%$ of the sires had 2 to 10 daughters and about $10 \%$ of them had 11 or more female progeny. Pedigree information contained sires and dams as
Table 1 Distribution of cows and sires of cows by lactation number

\begin{tabular}{lcc}
\hline \hline & No. of cows & No. of sires \\
\hline Lactation 1 & 5277 & 321 \\
Lactation 2 & 3557 & 358 \\
Lactation 3 & 2357 & 384 \\
Total & 6352 & 476 \\
\hline \hline
\end{tabular}

far as three generations back, so in total, 10440 animals were in the pedigree file.

\section{Trait definition}

Milkability. Information was available on three milkability traits: average milk flow rate $(\mathrm{kg} / \mathrm{min})$, maximum milk flow rate $(\mathrm{kg} / \mathrm{min})$ and total milking time (min). On farm 1 , all cows were milked twice a day and traits were recorded at every milking using automated units by ALPRO-De Laval. On farm 2, a proportion of the cows were milked thrice, the others were milked twice resulting in two or three records per day from every cow and the three milkability traits were also recorded at every milking using automated units by METATRONWestfaliaSurge. In the present study, the milkability data were recorded by two different milking equipment manufacturers but were treated as the same trait.

Milkability traits per milking were pooled into daily values for several reasons. One of them was the reduction of the amount of data. In addition, in Germany, the BV estimation for other traits, such as milk yield, fat, protein and SCC, also uses daily values as an observation unit. Genetic correlations to other important traits are needed in the case of the inclusion of milkability in a total merit index. Difficulties in the handling of the data may appear during estimation of genetic correlations if milkability information is available for every single milking while data from other traits such as milk yield or SCC are provided as daily averages.

The daily values with respect to milking time resulted from summing the milking times from the single milkings each day. The daily value for maximum milk flow rate corresponded to the highest value for this trait recorded during a single day. This decision was made because the trait was used to characterise the maximum milk flow that was achieved during the whole milking, and the daily value for this trait had to be at least as high as that in the single milkings of the day. The daily value for average milk flow was attained by weighting the several values per day with the respective milk yields.

The resulting dataset consisted of 2188810 daily values for each trait. Only the records between day 8 and day 305 after calving from first to third parity were considered. Information on SCC was available monthly for every cow. Original data from milk recording was cells per $\mathrm{ml}$ milk and had to be transformed to get a standard normal distribution. This logarithmic transformation to the somatic cell score (SCS) was done according to the 
Table 2 Means and standard deviations (s.d.) of the three milkability traits average milk flow, maximum milk flow and milking time and of somatic cell score (SCS) in the study population

\begin{tabular}{lrrr}
\hline \hline & $n$ & Mean & s.d. \\
\hline Average milk flow (kg/min) & 2188810 & 2.3 & 0.6 \\
Maximum milk flow (kg/min) & 2188810 & 4.0 & 1.3 \\
Milking time (min) & 2188810 & 12.9 & 4.1 \\
SCS & 66146 & 3.0 & 1.6 \\
\hline \hline
\end{tabular}

international standard. Summary statistics of the dataset are given in Table 2 .

Mastitis. Medical treatments with respect to mastitis were undertaken and recorded by veterinarians or farm staff. The period of lactation was considered to have started on the date of calving and ended after 305 days of lactation, and again data were considered from first to third parity. The mastitis data were obtained from the same cows that provided the milkability data. Overall, 2600302 records were available; one observation per day for each cow. Each observation was allocated a mastitis code. If a treatment was recorded, the day of treatment and the following 5 days were coded with ' 1 '. All other days were coded with ' 0 '. The 5 -day period was chosen because it was the average time in which milk had to be discarded.

Information on medical treatments of the cows was used to define two different mastitis traits; namely mastitis occurring between day 1 and day 50 of lactation (mastitis 50d) and mastitis occurring between day 1 and day 305 of lactation (mastitis 305d).

The estimation of the variance components and BVs was carried out for both mastitis traits. Mastitis 50d was chosen as most cases of mastitis occurred in the first 50 days of lactation (Figure 1) and to reduce the amount of data and thus the computation time. The data-collecting period for the second dataset ended at 305 days of lactation, corresponding to the period during which milkability was recorded.

The frequencies of days with treatments were between $0.7 \%$ and $1.2 \%$ for the first three lactations during the first 305 days in milk, i.e. treatment days were between $0.7 \%$ and $1.2 \%$ of the test-days in the respective datarecording period. Further summary statistics of the mastitis dataset are given in Table 3.

\section{Statistical analysis}

Milkability. The significance of fixed effects on the milkability traits was calculated by using the Mixed Procedure (Statistical Analysis Systems Institute, 2000). The following effects were tested for significance: parity, day of lactation and herd test-day. Additionally, we tested the effect of age at calving, as recommended by Hinrichs et al. (2005). The effect of age at calving in our study

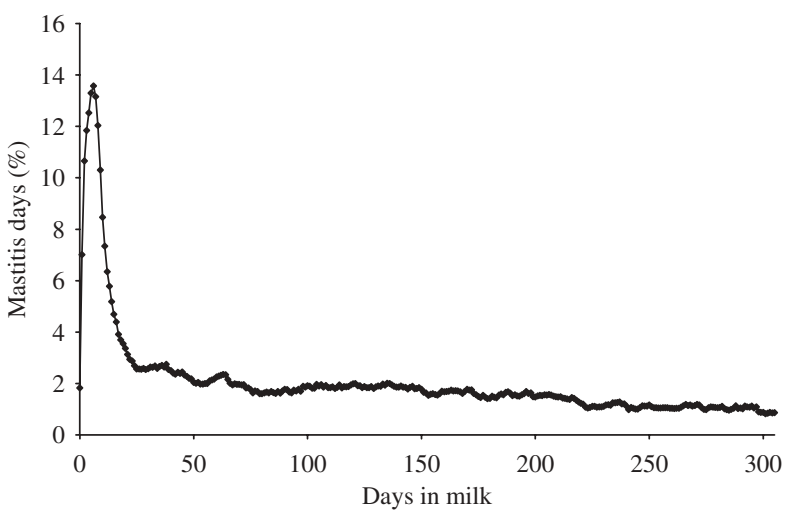

Figure 1 Distribution of mastitis days in the first 305 days of lactation, based on the first three lactations of 6352 cows.

Table 3 Mastitis prevalence in the first three lactations between the day of calving and day 305 of lactation

\begin{tabular}{llcc}
\hline \hline & \multicolumn{3}{c}{ Lactation } \\
\cline { 2 - 4 } & \multicolumn{1}{c}{1.} & 2. & 3. \\
\hline $\begin{array}{l}\text { Observation days } \\
\text { Treatment days }\end{array}$ & 1195822 & 860749 & 543731 \\
$\quad$ Absolute & 8515 & 8489 & 6484 \\
$\quad$ Relative & $0.7 \%$ & $1.0 \%$ & $1.2 \%$ \\
Mastitis days & & & \\
$\quad$ Absolute & 20867 & 20094 & 15352 \\
$\quad$ Relative & $1.7 \%$ & $2.3 \%$ & $2.8 \%$ \\
\hline \hline
\end{tabular}

was examined by subdividing each parity and including the lactation number, with lactation numbers 1 and 2 each divided into three different classes: 1 (20 to 25 months), 2 (26 to 28 months), 3 (29 to 40 months) for lactation 1 , and 4 (30 to 39 months), 5 (40 to 43 months), and 6 (44 to 56 months) for lactation 2, respectively. Age at calving class 7 (45 to 75 months) corresponded with lactation 3. Variance components were estimated by REML using the VCE 4 package (Neumaier and Groeneveld, 1998). The variance component estimations were performed within every milkability trait due to the large amount of data and associated problems with computation time.

In a first step, within every milkability trait the following multitrait animal model was used, with the milkability data from different parities assumed to be different traits:

$$
\begin{aligned}
y_{j k l m}= & \mu+D_{j}+b_{1}(D / c)+b_{2}(D / c)^{2}+b_{3} \ln (c / D) \\
& +b_{4}[\ln (c / D)]^{2}+a_{k}+p e_{l}+e_{j k l m},
\end{aligned}
$$

where $y_{i k l m}=$ average milk flow rate from parities 1 to 3 , maximum milk flow rate from parities 1 to 3 and milking time from parities 1 to 3 , respectively, $\mu=$ mean, $D_{j}=$ effect of herd test-day $(j=1-5388), a_{k}=$ random additive genetic effect $(k=1-10440), \quad p e_{l}=$ random permanent environmental effect to account for repeated 
measures within cow $(I=1-6352)$ and $e_{j k l m}=$ random error. Following Ali and Schaeffer (1987), the stage of lactation was considered as a regression with four coefficients. $b_{1}$ and $b_{2}$ are regression coefficients on the linear and quadratic effect of the ratio $D / c$, in which $D$ is the day in lactation and $c$ is a constant, in this case $c=325 . b_{3}$ and $b_{4}$ are regression coefficients on the linear and quadratic effect of $\ln (c / D)$. The effect of the herd test-day is a multicode of the test-day, the farm and the milking frequency to consider the environmental effect of the farm on each day. Cows milked thrice a day within farm 2 were allocated another herd test-day compared with the cows milked only twice a day.

In a second step, the following animal repeatability model was applied assuming that milkability was equally genetically determined in different parities:

$$
\begin{aligned}
y_{i j k l m}= & \mu+L_{i}+D_{j}+b_{i 1}(D / c)+b_{i 2}(D / c)^{2}+b_{i 3} \ln (c / D) \\
& +b_{i 4}[\ln (c / D)]^{2}+a_{k}+p e_{l}+e_{i j k l m},
\end{aligned}
$$

where $y_{i j k l m}=$ average or maximum milk flow rate $(\mathrm{kg} /$ min) or milking time (min), $\mu=$ mean, $L_{i}=$ effect of parity $(i=1-3), D_{j}=$ effect of herd test-day $(j=1-5388)$, $a_{k}=$ random additive genetic effect $(k=1-10440)$, $p e_{l}=$ random permanent environmental effect to account for repeated measures within cow $(I=1-6352)$ and $e_{i j k l m}=$ random error. Following Ali and Schaeffer (1987), the stage of lactation was considered as a regression with four coefficients within parity. $b_{i 1}$ and $b_{12}$ are regression coefficients on the linear and quadratic effect of the ratio $D / c$, in which $D$ is the day in lactation and $c$ is a constant, in this case $c=325 . b_{B 3}$ and $b_{i 4}$ are regression coefficients on the linear and quadratic effect of $\ln (c / D)$. The fixed effects included in the models 1 and 2 were chosen in reference to a previous study (Gäde et al., 2006) and because they were significant in the analysis of variance. For the SCS, model 2 was applied with 165 herd test-days $(j=1$ to 165$), 10009$ additive genetic effect levels and 5909 permanent environmental effect levels.

The genetic correlations between the milkability traits and between the milkability traits and SCC were estimated bivariately.

BVs for the milkability traits were estimated by using the PEST software package (Groeneveld, 1990) with model 2.

Mastitis. Variance components for mastitis were analysed univariately using a threshold animal model. In the model, an unobservable normally distributed variable (liability) is assumed for each observation. When the liability exceeds a certain threshold, the outcome of the trait falls into the next category (Falconer and Mackay, 1996). It was assumed that mastitis was the same trait each day of lactation in all lactations, and following Hinrichs et al. (2005) the animal repeatability test-day model given below was chosen:

$$
\lambda_{i j k l m}=H_{i}+P_{j}+f_{j(\mathrm{DIM})}+p_{k}+a_{l}+e_{i j k l m},
$$

where $\lambda_{i j k l m}=$ the unobservable liability to mastitis of the respective observation, $H_{i}=$ the fixed effect of the ith herd test-week of observation, $P_{j}=$ the fixed effect of the jth parity, $f_{j(D I M)}=$ the lactation curve nested within parity $j, p_{k}=$ the random permanent environmental effect of the $k$ th cow, $a_{l}=$ the random effect of the th animal and $e_{i j k l m}=$ the residual effect. $f_{j(\mathrm{DIM})}$ is a fixed effect for the first 7 days of lactation. After the seventh day of lactation $f_{j(\mathrm{DIM})}$ is identical to the function used by Ali and Schaeffer (1987). Similar to the model for the milkability traits, the herd test-week was included instead of the herd test-day. Due to the large average herd size, the fixed effect of herd test-week of observation had no extreme categories, i.e. fixed effect levels with no variation with respect to mastitis.

The Bayesian posterior distributions of the permanent environmental variance and the additive genetic variance of the liabilities for the different traits were determined through Gibbs sampling as implemented in the program LMMG_MTH (Reinsch, 1996). The liability values were generated by data augmentation, as described by Sorensen et al. (1995), drawing random variables from truncated normal distributions, which are conditional upon the other fixed and random effects in the model.

The Gibbs sampler was run in a single, long-chain scheme. The sampler ran 100000 rounds. Convergence was determined by visual inspection. The results of the first 30000 iterations were discarded (burn-in), and the remaining iterations were used to estimate the variance components. The posterior mean of the additive genetic variance and the permanent environmental variance were estimated as the mean of all iteration estimates, following Sorensen et al. (1995). For the estimation of BLUP BVs, the same Gibbs sampling algorithm was used a second time, but the variance components were kept fixed at their estimated values. The posterior mean of the random animal effects provided estimates of BVs on the liability scale. The reliabilities for the BVs $\left(R_{i}\right)$ were estimated by

$$
R_{i}=1-\mathrm{PEV}_{i} / \sigma_{a}^{2},
$$

where $\mathrm{PEV}_{i}=$ the predicted error variance of animal $i$, which was approximated by the variance of the estimated iteration animal effects and $\sigma_{a}^{2}=$ the posterior mean of the additive genetic variance. The BVs on the underlying liability scale were transformed to the phenotypic scale using

$$
p_{i}=\Phi\left(\mu+\mathrm{BV}_{i}\right),
$$

where $p_{i}=$ the probability that animal $i$ shows mastitis at day $x, \Phi()=$. the cumulative probability function of the standard normal distribution, $\mu=$ the probit function corresponding to the mean liability of mastitis and $\mathrm{BV}_{i}=$ the predicted $\mathrm{BV}$ on the liability scale for mastitis of animal $i$. BV for mastitis and SCS were multiplied by $(-1)$ such that higher breeding would represent better udder health. 
The relative breeding values (RBVs) with a mean of 100 and a true standard deviation of 12 for all traits for animal $i$ were calculated with the following formula:

$$
\mathrm{RBV}_{i}=\text { breeding value }_{i} / \sigma_{a}^{2} \times 12+100
$$

The reference population for standardisation of BVs were the base animals of the pedigree.

\section{Correlation between milkability and mastitis}

Pearson correlation coefficients were calculated between the respective BVs of the sires for average milk flow and mastitis 50d and mastitis 305d. Product-moment correlations between BVs are strongly influenced by reliability. This kind of correlation is likely to be lower in magnitude than directly estimated genetic correlations. Therefore, the estimated Pearson correlation coefficients were approximated to genetic correlations by considering the reliabilities of the BVs as proposed by Blanchard et al. (1983):

$$
r_{g 1,2}=\frac{\sqrt{\left(\sum_{i=1}^{n} R_{1 i}\right)\left(\sum_{i=1}^{n} R_{2 i}\right)}}{\left(\sum_{i=1}^{n} R_{1 i} R_{2 i}\right)} \times r_{1,2},
$$

where $n$ was the number of sires with observations, and $R_{1}$ and $R_{2}$ were the reliabilities of the $\mathrm{BV}$ of the respective milkability trait and the respective mastitis trait, and $r_{1,2}$ was the Pearson correlation between the BVs.

Furthermore, the predicted BV for average milk flow and SCS (Figure 2) and for average milk flow and mastitis (Figure 3), respectively, were illustrated graphically. Additionally, the milk flow BVs of the sires were divided into four classes and the corresponding mean BVs for SCS and mastitis were calculated. Both were supposed to give information about a potential non-linearity between the functional traits milk flow and udder health.

\section{Results}

\section{Choice of the model}

Milkability. We tested the effect of age of calving. As the different ages of calving within parity did not show an influence on the milkability traits (Figure 4), the model was simplified and therefore only included the effect of parity instead of the effect of age at calving. According to the lactation curves for milkability, an interaction between parity and stage of lactation was observed. The lactation curves for the milk flow (Figure 4) were almost constant in the heifers and decreasing in the cows of second and third parity. An intersection of curves of heifers and cows appeared. Therefore, the interaction between the stage of lactation and cow parity should be considered in models for genetic analysis of milkability traits. Vicario et al. (2006) showed similar lactation curves for first parities $v$. other parities.

Applying a multiple trait model within the three milkability traits (model 1) resulted in genetic correlations

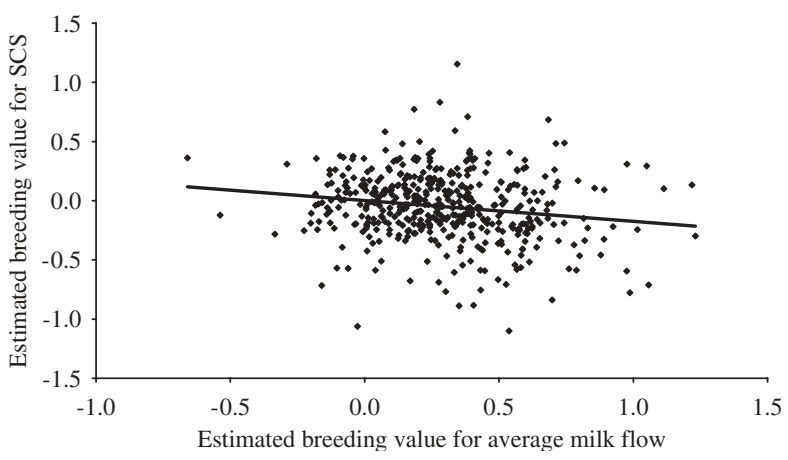

Figure 2 Breeding values for average milk flow and somatic cell score (SCS) (all sires: $n=465$ ).

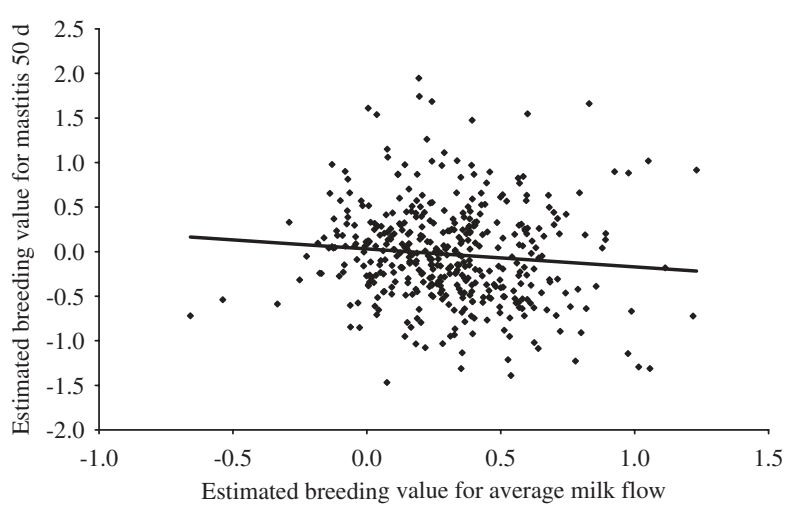

Figure 3 Breeding values for average milk flow and mastitis 50 days (all sires: $n=419$ ).

between different parities of $r_{g}=0.88$ to 0.98 . These genetic correlations were sufficiently high to warrant a repeatability model (Table 4).

\section{Variance components}

Milkability. The computed heritabilities (Table 5) were at a high level with $h^{2}=0.42$ for average milk flow, $h^{2}=0.56$ for maximum milk flow and $h^{2}=0.38$ for milking time. The genetic correlation coefficients between the milkability traits (Table 5) were $r_{g}=0.91$ between average and maximum milk flow, $r_{g}=-0.77$ between average milk flow and milking time and $r_{g}=$ -0.84 between maximum milk flow and milking time.

Mastitis. The estimated additive genetic variance and heritability from the 305 test-day model were lower compared with the estimates from the 50 test-day model (Table 6). The respective heritability estimates were $h^{2}=0.13$ and 0.19 .

\section{Breeding values}

The mean RBV for the milk flow traits (average and maximum milk flow) of the sires were greater than 100 , and the RBV for the udder health traits (SCS, mastitis $50 \mathrm{~d}$ and mastitis 305d) were lower than the mean RBV of the base animals (Table 7). 
Gäde, Stamer, Bennewitz, Junge and Kalm

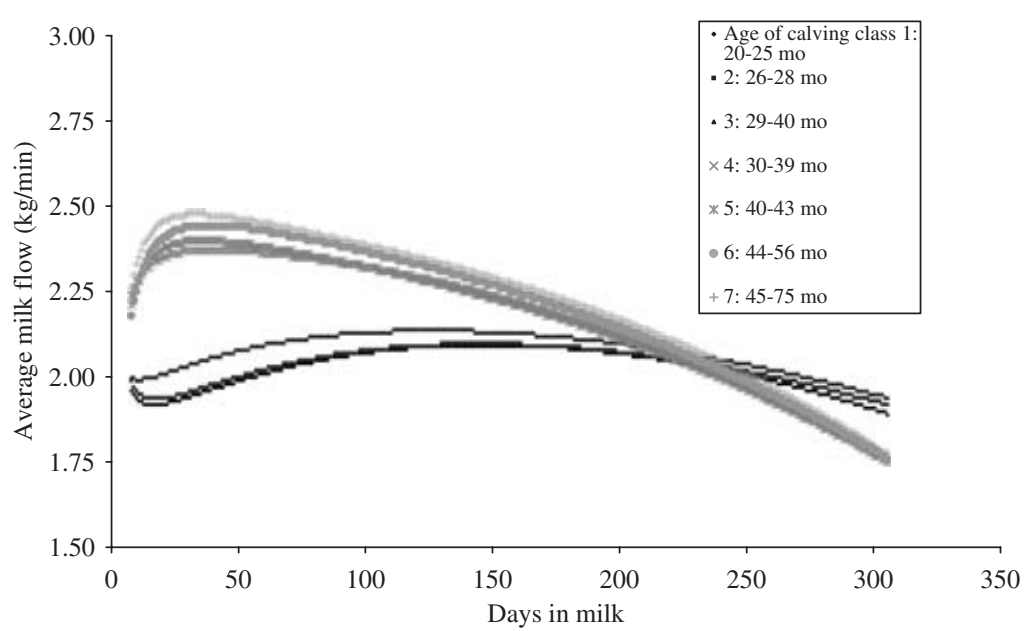

Figure 4 Development of the average milk flow $(\mathrm{kg} / \mathrm{min})$ for the different calving age classes, with classes 1 to 3 corresponding to first parity, classes 4 to 6 corresponding to second parity and class 7 corresponding to third parity.

Table 4 Genetic correlations (with standard errors in parentheses) between the three milkability traits (average milk flow, maximum milk flow and milking time) in the first three lactations in 6352 German Holstein cows

\begin{tabular}{lccc}
\hline \hline & $\begin{array}{c}\text { Average } \\
\text { milk flow }\end{array}$ & $\begin{array}{c}\text { Maximum } \\
\text { milk flow }\end{array}$ & Milking time \\
\hline Lactation 1-2 & $0.91(0.01)$ & $0.97(0.00)$ & $0.93(0.01)$ \\
Lactation 1-3 & $0.88(0.01)$ & $0.93(0.01)$ & $0.92(0.01)$ \\
Lactation 2-3 & $0.95(0.01)$ & $0.98(0.01)$ & $0.97(0.01)$ \\
\hline \hline
\end{tabular}

Another possibility is to express the BVs on the phenotypic scale. These can give an idea of the scope for genetic improvement by selection. An RBV for example of 100 for mastitis $50 \mathrm{~d}$ corresponds to a BV of $4.9 \%$ on the phenotypic scale. This expected value means that $4.9 \%$ of all days in milk of the respective animal could be coded as mastitispositive according to our definition of mastitis. Figure 5 illustrates the variation of the sires' predicted BVs on the phenotypic scale for mastitis $50 \mathrm{~d}$. They vary from $0 \%$ for the best sire to up to $43 \%$ for the worst.

\section{Relationship between milkability and udder health}

The genetic correlation coefficients were $r_{g}=0.35,0.38$ and -0.24 , respectively, between SCS and the milkability traits average milk flow, maximum milk flow and milking time (Table 5), indicating that cows which milk more quickly also tend to show higher SCS. The approximated genetic correlation coefficients between the three milkability traits and mastitis 50d and mastitis 305d (Table 8) indicated that a higher milk flow and a shorter milking duration, respectively, are associated with an increased susceptibility to mastitis.

Figure 6 presents the corresponding mean BVs for SCS, mastitis $50 \mathrm{~d}$ and mastitis $305 \mathrm{~d}$ in the various categories of average milk flow BVs. The mean BVs for all three udderhealth traits decreased with increasing milk flow.

\section{Discussion}

\section{Choice of the model}

Milkability. Because existing milkability information generally only consists of singularly recorded milkability from the first parity, to our knowledge, little is known in the literature about the genetic correlation between milkability in different parities. That is why applying a multiple trait model (model 1) was performed to test whether the milkability should be considered as different traits in different parities. The genetic correlations between different parities within the three milkability traits were shown to be sufficiently high to warrant a repeatability model (Table 4). Therefore, when estimating BVs for milkability, using the information out of first parity only may be sufficient, thus resulting in a shorter generation interval.

Longitudinal data as in the present study consist of repeated observations across time and allow the investigation of time-dependent fixed and random effects. Analysing test-day yields by random regression methodology results in stage-of-lactation-specific heritabilities and genetic correlations and it is intended that these results will be published at a later date.

Mastitis. It is of interest to study whether mastitis can be considered to be the same trait in first and later lactations. Genetic correlations much lower than 1 indicate that mastitis cannot be regarded as the same trait in different stages of lactation or in different lactations. This implies that a multivariate threshold model treating mastitis in different stages of lactation as different traits may be required for genetic evaluation.

Few estimates of genetic correlations between susceptibility to mastitis in different lactations have been reported (Heringstad et al., 2004) and these estimates differ from each other. Some studies have found high genetic correlations among parities, implying the use of a 
Table 5 Heritabilities (on the diagonal), permanent environmental correlations (above the diagonal) and genetic correlations (below the diagonal) with their standard errors in parentheses for the three milkability traits average milk flow, maximum milk flow and milking time and for somatic cell score (SCS) in 6352 German Holstein cows
(1)
(2)
(3)
(4)

(1) Average milk flow ( $\mathrm{kg} / \mathrm{min})$

(2) Maximum milk flow $(\mathrm{kg} / \mathrm{min})$

$0.42(0.02)$
$0.91(0.01)$
$-0.77(0.02)$
$0.35(0.05)$

$0.82(0.01)$
$0.56(0.02)$
$-0.84(0.02)$
$0.38(0.05)$

$-0.51(0.02)$

$-0.35(0.01)$

$-0.17(0.03)$

(3) Milking time ( $\mathrm{min})$

$0.35(0.05)$

$0.38(0.05)$

$0.38(0.05)$

$-0.03(0.02)$

$0.01(0.03)$

(4) SCS

$-0.24(0.05)$

$0.11(0.01)$

Table 6 Posterior means (standard deviations in parentheses) of additive genetic $\left(\sigma_{\mathrm{a}}^{2}\right)$ and permanent environmental variance $\left(\sigma_{\mathrm{pe}}^{2}\right)$, heritabilities $\left(\mathrm{h}^{2}\right)$ and repeatabilities $(\mathrm{w})$ of mastitis based on 50 and 305 days of lactation

\begin{tabular}{lcccc}
\hline \hline & $\sigma^{2}{ }_{a}$ & $\sigma_{p e}^{2}$ & $h^{2}$ & $w^{\dagger}$ \\
\hline Mastitis $50 \mathrm{~d}^{\ddagger}$ & $0.93(0.14)$ & $2.98(0.16)$ & $0.19(0.03)$ & $0.80(0.01)$ \\
Mastitis $305 \mathrm{~d}^{\ddagger}$ & $0.33(0.05)$ & $1.25(0.06)$ & $0.13(0.02)$ & $0.61(0.01)$
\end{tabular}

${ }^{+} w=\left(\sigma_{a}^{2}+\sigma_{p e}^{2}\right) /\left(\sigma_{a}^{2}+\sigma_{p e}^{2}+\sigma_{e}^{2}\right), \sigma_{e}^{2}$ was set to 1 .

${ }^{\ddagger}$ Mastitis until day 50 (50d); mastitis until day 350 (305d).

Table 7 Relative breeding values (RBV) of sires and corresponding reliabilities for the three milkability traits average milk flow, maximum milk flow and milking time, for somatic cell score (SCS) and for mastitis until day 50 (mastitis 50d) and day 305 of lactation (mastitis 305d)

\begin{tabular}{lrrrrrc}
\hline \hline & & & & & & $\begin{array}{c}\text { Mean } \\
\text { Trait }\end{array}$ \\
& $n$ & Mean & s.d. & Min. & Max. & reliability (\%) \\
\hline Average milk flow & 476 & 108.6 & 8.2 & 80.0 & 137.3 & 54.3 \\
Maximum milk flow & 476 & 101.4 & 8.1 & 71.3 & 127.5 & 58.5 \\
Milking time & 476 & 98.9 & 7.7 & 78.1 & 152.6 & 53.1 \\
SCS & 465 & 98.8 & 7.0 & 73.0 & 128.3 & 39.0 \\
Mastitis 50d & 419 & 99.6 & 7.0 & 81.1 & 125.1 & 34.3 \\
Mastitis 305d & 472 & 95.8 & 12.5 & 55.6 & 149.5 & 34.5 \\
\hline \hline
\end{tabular}

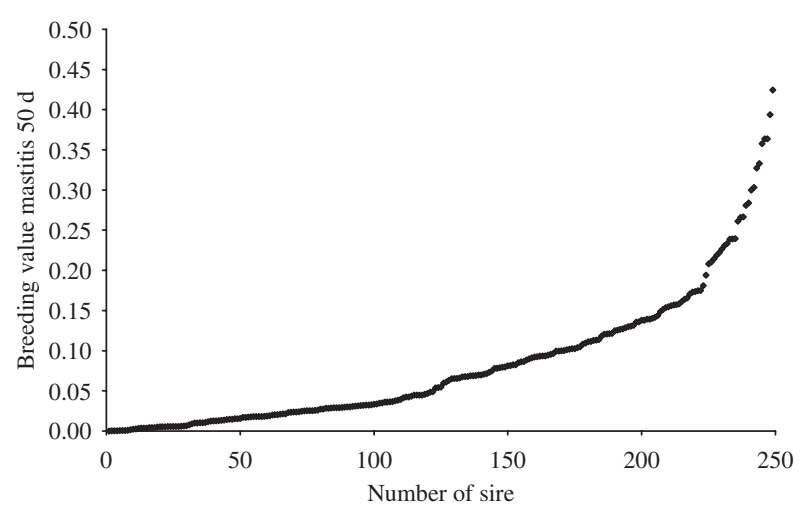

Figure 5 Predicted breeding values for mastitis until day 50 of lactation (mastitis 50d) expressed on the phenotypic scale for sires with at least five daughters $(n=249)$.

repeatability model, and others have obtained estimates suggesting interval-specific genetic control of resistance to mastitis. Nielsen et al. (1999) estimated genetic correlations between mastitis in the first three lactations
Table 8 Pearson correlation coefficients $\left(\mathrm{r}_{\mathrm{BV}}\right)$ and approximated genetic correlations $\left(\mathrm{r}_{\mathrm{g}}\right)$ between relative breeding values (RBV) for the three milkability traits average milk flow, maximum milk flow and milking time and for mastitis until day 50 (mastitis 50d) and day 305 of lactation (mastitis 305d)

\begin{tabular}{|c|c|c|c|c|}
\hline & \multicolumn{4}{|c|}{ Sires with at least 10 daughters } \\
\hline & \multicolumn{2}{|c|}{$\begin{array}{c}\text { Mastitis } \\
\text { 50d (143 sires) }\end{array}$} & \multicolumn{2}{|c|}{$\begin{array}{c}\text { Mastitis } \\
\text { 305d (154 sires) }\end{array}$} \\
\hline & $r_{B V}$ & $r_{g}^{\dagger}$ & $r_{B V}$ & $r_{g}^{+}$ \\
\hline Average milk flow & -0.08 & -0.15 & -0.16 & -0.30 \\
\hline Maximum milk flow & -0.23 & -0.33 & -0.21 & -0.29 \\
\hline Milking time & 0.18 & 0.26 & 0.15 & 0.21 \\
\hline
\end{tabular}

${ }^{+}$Corrected for reliabilities according to Blanchard et al. (1983).

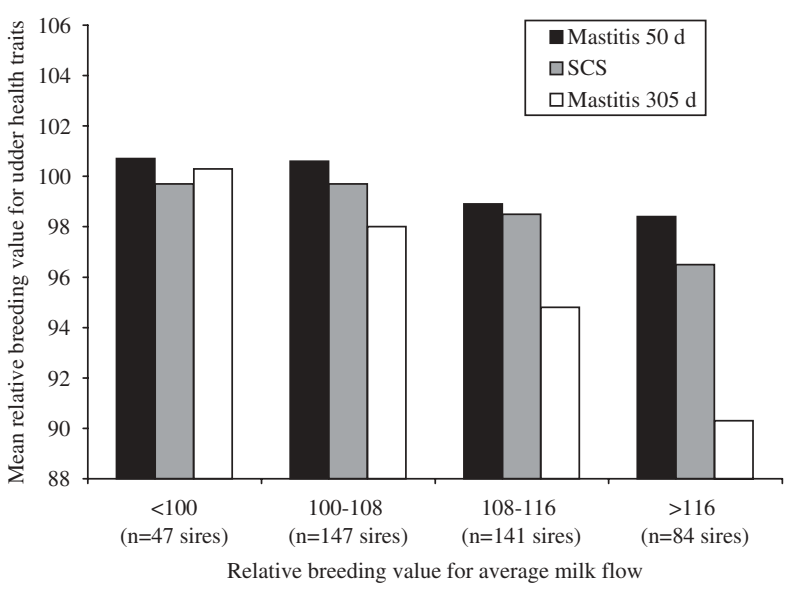

Figure 6 Mean relative breeding value (RBV) for the three udder-health traits somatic cell score (SCS), mastitis until day 50 of lactation (mastitis $50 \mathrm{~d}$ ) and mastitis until day 305 of lactation (mastitis 305d) by the category of RBVs for average milk flow in all sires $(n=419)$.

in Danish Holsteins to be between 0.85 and 0.98 . Pösö and Mäntysaari (1996) found genetic correlations ranging from 0.67 to 0.90 between mastitis in the first three lactations in Finnish Ayrshire. Lund et al. (1999) found genetic correlations of $0.89,0.80$ and 0.67 between clinical mastitis in early lactation ( -10 to 50 days after first calving) and in the periods 50 to 180 days, 180 to 350 days and 50 to 350 days after first calving, respectively.

Heringstad et al. (2004) found genetic correlations of liability to mastitis between intervals ranging between 0.24 
and 0.73 and Zwald et al. (2006) estimated genetic correlations between mastitis resistance in the first three lactations ranging from 0.42 to 0.49 , indicating that mastitis resistance may be a genetically different trait in the first lactation vs. later lactations or at different intervals.

Following Hinrichs et al. (2005) and a large part of the literature, a repeatability model was chosen in the present study, meaning mastitis was assumed to be the same trait at each day of lactation and in all lactations.

\section{Variance components}

Milkability. The computed heritabilities (Table 5) were at a high level for average milk flow, maximum milk flow and milking time. Selection for good milkability thus seems to have promise. In a previous study (Gäde et al., 2006), the heritabilities estimated based on daily values for serial milkability from an automatic milking system were $h^{2}=0.55$ for average milk flow, $h^{2}=0.55$ for maximum milk flow and $h^{2}=0.39$ for milking time, thus being similar to the respective estimates from the present study. In contrast, estimates for serially recorded milking speed from Karacaören et al. (2006) using daily test-day random regression methodology were considerably lower varying from $h^{2}=0.003$ to $h^{2}=0.098$ for day 1 to day 305 of lactation. However, the sample size was low ( $n=320$ cows). Zwald et al. (2005) estimated a heritability of $h^{2}=0.17$ for serially recorded milking duration. In the present study, the higher heritabilities can be explained by more standardised environmental conditions existing on the farms. The genetic correlation coefficients between the milkability traits (Table 5) were similar to the respective estimates from the study of Gäde et al. (2006) $\quad\left(r_{g}=0.97,-0.90\right.$ and -0.85 , respectively). The correlation coefficients were close to unity and indicated that selection based on one of the three milkability traits may be sufficient.

Mastitis. The estimated additive genetic variances and heritabilities from the 50 and the 305 test-day models suggested that mastitis in earlier stages of lactation when the cows are facing high physiological demands was more related to the cows' genetic character, whereas mastitis in the later phases of lactation was more affected by random, genetically unrelated events. In consequence, it may be recommendable to consider the information on mastitis in the first 50 days of lactation, in order to select cows with lower susceptibility to mastitis. The first 50 days of lactation have the advantage that most cases of mastitis occur in this stage of lactation (Figure 1). Additionally, the BVs for mastitis in early lactation will be available earlier than those for mastitis in the whole lactation.

\section{Breeding values}

The average BV at the base of the population is equal to zero and the corresponding RBV is 100 . By looking at the mean BVs of the sires, it is possible to discover a positive or negative selection gain. For the milkability traits, the mean BVs of the sires indicated a selection gain insofar as the bulls showed the genetic disposition for higher milk flow and shorter milking duration. The higher milk flow could be partly a result of selection for a higher milk yield as the genetic correlation between milk yield and average milk flow is positive (Trede, 1987; Bahr et al., 1995; Santus and Bagnato, 1998). We estimated a distinct positive genetic correlation between milk yield and average milk flow of $r_{g}=0.51$ in a previous study (Gäde et al., 2006). Accordingly, Vicario et al. (2006) observed a genetic improvement of milkability that amounted to about half a standard deviation in 10 years in Italian Simmentals. In contrast, the mean RBV of lower than 100 for the udder health traits SCS, mastitis $50 \mathrm{~d}$ and mastitis 305d in Table 7 indicated a slightly negative selection progress; that is, the daughters of the bulls may exhibit an udder health below the base population mean. This supports the importance of considering udder health to a greater extent in selection processes. In a study by Heringstad et al. (2004) with Norwegian dairy cattle, a genetic improvement in resistance to mastitis after 1986 was shown as a result of taking into account mastitis resistance in Nordic breeding programmes in Norway, Sweden, Finland and Denmark for many years.

The variation of the sires' predicted BVs on the phenotypic scale for mastitis $50 \mathrm{~d}$ in Figure 5 gives an impression of the scope for genetic improvement by selection. Figure 5 indicated that there is a considerable scope for selection on mastitis.

\section{Relationship between milkability and udder health}

Looking at the genetic correlation coefficients between SCS and the three milkability traits in Table 5 and the approximated genetic correlation coefficients between the three milkability traits and mastitis $50 \mathrm{~d} / 305 \mathrm{~d}$ in Table 8 , a higher milk flow and a shorter milking duration, respectively, seem to be associated both with increased SCCs and with increased susceptibility to mastitis.

In case of the existence of a non-linear relationship between milkability and udder health, the correlation coefficient may not be capable of reflecting the relationship satisfactorily (Roth et al., 1998). Therefore, the respective predicted BVs were illustrated graphically. The graphic illustration of the distribution of the predicted BVs for average milk flow and SCS (Figure 2) and of the predicted BVs for average milk flow and mastitis 50d (Figure 3) suggested a linear relationship between milkability and udder health.

The classes of average milk flow BVs in Figure 6 did not have 100 as their mean, which may appear confusing. This came about because we considered the increased mean of the sires' BVs for average milk flow (Table 7). The bar graph in Figure 6 also demonstrated a linear relationship between milkability and udder health, indicating that the higher the BVs for milk flow, the lower the BVs for SCS, mastitis 50d and mastitis 305d. Roth et al. (1998) divided the milk flow 
traits into classes also and the respective least-square means for the udder-health traits SCC and bacteriological diagnosis were assigned to the milk flow classes. The authors obtained an indication of the existence of a cowspecific optimal range of milkability, highlighting a nonlinear relationship between milkability and udder health. Zwald et al. (2005) divided sires into three groups based on the predicted transmitting abilities (PTA) for milking duration and found that sires transmitting shorter milking duration tended to transmit higher SCS. With respect to mastitis, the authors found a non-linear relationship because the probability of clinical mastitis among daughters was slightly higher for sires that transmitted extremely fastor slow-milking speeds, but the relationship was not significant. In agreement with the present study, Rensing and Ruten (2005) showed an unfavourable genetic correlation between the RBV for milking speed and SCS, with an approximated genetic correlation of 0.23 , and over the whole range of classes of relative BVs, RBV for milking speed and SCS were almost linearly correlated.

Because of the positive genetic correlation between milk yield and average milk flow (Gäde et al., 2006) and the generally accepted unfavourable genetic correlation between milk yield and mastitis (Hinrichs et al., 2005), further selection for higher milk yield may be accompanied by an increase in milk flow and a deterioration in udder health. The average RBV of the sires in the present study, showing a higher milk flow and poorer udder health compared with the population mean, may be in line with the issue described.

So far, the main objective of the genetic evaluation of milkability has been to improve labour efficiency (Dodenhoff et al., 1999) since more than half of the work in milk production is needed for milking. But in view of the relationship to udder health and the increasing focus on functional traits, the future main objective of the genetic evaluation of milkability may be to contribute to an improvement in udder health, by avoiding excessively high milk flow rates. A medium milk flow rate may be favoured, which means that neither slow- nor very fast-milking cows are wanted. It is suggested that animals with a high milkability should be excluded from breeding in order to prevent a probable genetic deterioration in udder health.

The results show that the establishment of a special datarecording scheme for functional traits such as milkability and mastitis may be possible on commercial dairy farms. Such data-recording would lead to large field datasets that could be used for the estimation of genetic parameters and BVs. The establishment of data-recording schemes should proceed stepwise. In a first step, potential data-recording farms would have to be selected. These farms would have to fulfil several requirements. They ought to be as large as possible, and farm management, farm staff, and veterinarians would have to be interested in the data-recording scheme. Furthermore, all farms would require computerbased herd management programs. The same bulls should be used for artificial insemination across the data-recording farms to ensure a genetic connection between the farms. In line with this, Zwald et al. (2006) demonstrated the potential usefulness of farmer-recorded clinical mastitis data in selection programmes. In the near future, an individual breeding company may be able to collect mastitis data from a subset of large herds that have the appropriate software and tend to record clinical mastitis cases diligently. This kind of performance test presents a future solution for the handling of functional traits in breeding, such as milkability and mastitis. Such testing allows additional traits to be recorded on large farms according to the future production environment and offers a good return on the input of supervision for information gained.

Methods for recording and storing the milkability data can differ between different milking equipment companies and different herd management software programs, thus creating inconsistencies in the type of the data that are available from different herds. If the genetic correlations are sufficiently high, differently recorded milkability information may be treated as the same trait. In the present study, the milkability data from the two farms were recorded from two different milking equipment manufacturers and were equivalently used for trait definition. In case of low genetic correlations, the serial milkability that is collected by different techniques and diverse manufacturers must be treated as different traits in a multitrait model. The challenge is to implement new standards for data-recording and exchange. To establish new standards, great efforts will be needed on behalf of the breeding organisations because neither the management software suppliers nor the milk recording organisations are currently interested in investing in this field (Rensing, 2005). Following the approval of devices for milk yield recording by ICAR, it may be desirable to introduce an adequate approval of equipment for milkability recording.

\section{Conclusions}

The database used in this study was large and of high quality. A comparable investigation with this kind of database has not, to our knowledge, been previously performed. Serial information was available for every cow and for every day from multiple years on milkability and additionally on mastitis. The information came from practical farms with a genetic connection since the bulls had been used on both farms.

The high heritabilities for the milkability traits confirmed the outcome of a recent study (Gäde et al., 2006) that inclusion of milkability in breeding schemes may be advantageous. Because of the relationship with labour efficiency and udder health, it may be recommendable to consider milkability in breeding decisions. An attempt should be made to exclude those cows with low or high milk flow from breeding to achieve a more uniform milking duration among the cows and simultaneously to avoid deterioration in udder health. Thus, milkability has an intermediate optimum.

Concerning the question of whether the milkability information recorded by different milking equipment companies and different herd management software 
programs can be treated as the same trait, it may be desirable to introduce an adequate approval of equipment for milkability recording by ICAR, in the same manner as the approval of devices for milk-yield recording.

The results show that the establishment of a special data-recording scheme for functional traits such as milkability and mastitis on commercial dairy farms may be possible.

\section{Acknowledgements}

This project was supported by the Federal Ministry of Food, Agriculture and Consumer Protection (BMELV), Berlin, the NOG Nord Ost Genetic GmbH \& Co. KG, Verden, Germany, and by the Ministry of Education, Science, Research, and Culture of the Federal State of Schleswig-Holstein.

The manuscript has benefited from the critical and helpful comments of two anonymous reviewers.

\section{References}

Ali TE and Schaeffer LR 1987. Accounting for covariances among test day milk yields in dairy cows. Canadian Journal of Animal Science 67, 637-644.

Bahr T, Preisinger R and Kalm E 1995. Untersuchungen zur Zellzahl und Melkbarkeit beim Rind: 2 . Mitteilung: Genetische Parameter der Melkbarkeit. Züchtungskunde 67, 105-116.

Blanchard PJ, Everett RW and Searle SR 1983. Estimation of genetic trends and correlations for Jersey cattle. Journal of Dairy Science 66, 1947-1954.

Boettcher PJ, Dekkers JCM and Kolstad BW 1998. Development of an udder health index for sire selection based on somatic cell score, udder conformation and milking speed. Journal of Dairy Science 81, 1157-1168.

Dodenhoff D, Sprengel D, Duda J and Dempfle L 1999. Zucht auf Eutergesundheit mit Hilfe des Lactocorders. Züchtungskunde 71, 459-472.

Duda J 1995. Beziehungen zwischen Melkbarkeit und Mastitisanfälligkeit. Züchtungskunde 67, 467-476.

Falconer DS and Mackay TFC 1996. Introduction to quantitative genetics, fourth editionLongmann and Co, London.

Gäde S, Stamer E, Junge W and Kalm E 2006. Estimates of genetic parameters for milkability from automatic milking. Livestock Science 104, 135-146.

Göft H, Duda J, Dethlefsen A and Worstorff H 1994. Untersuchungen zur züchterischen Verwendung der Melkbarkeit beim Rind unter Berücksichtigung von Milchflußkurven. Züchtungskunde 66, 24-37.

Grindal RJ and Hillerton JE 1991. Influence of milk flow rate on new intramammary infection in dairy cows. Journal of Dairy Research 58, 263-268.

Groen AF, Steine T, Colleau JJ, Pedersen J, Pribyl J and Reinsch N 1997. Economic values in dairy cattle breeding, with special reference to functional traits. Report of an EAAP - Working Group. Livestock Production Science 49, $1-21$.

Groeneveld E 1990. PEST user's manual. Institute of Animal Husbandry and Animal Behaviour, FAL, Germany.

Heringstad B, Chang M, Gianola D and Klemetsdal G 2004. Multivariate threshold model analysis of clinical mastitis in multiparous Norwegian dairy cattle. Journal of Dairy Science 87, 3038-3046.

Hinrichs D, Stamer E, Junge W and Kalm E 2005. Genetic analysis of mastitis data using animal threshold models and genetic correlation with production traits. Journal of Dairy Science 88, 2260-2268.

Karacaören B, Jaffrezic F and Kadarmideen HN 2006. Genetic parameters for functional traits in dairy cattle from daily random regression models. Journal of Dairy Science 89, 791-798.
Lind B 2006. Ökonomische Gewichte für Merkmale des Gesamtzuchtwertes. 4. Rinder-Workshop, Uelzen 14./15.2.2006, Germany.

Lund MS, Jensen J and Petersen PH 1999. Estimation of genetic and phenotypic parameters for clinical mastitis somatic cell production deviance, and protein yield in dairy cattle using Gibbs sampling. Journal of Dairy Science 82, 1045-1051.

Luttinen A and Juga J 1997. Genetic relationships between milk yield, somatic cell count, mastitis, milkability and leakage in Finnish dairy cattle populations. Proceedings of the international workshop on genetic improvement of functional traits in cattle (GIFT) - health, Uppsala. Interbull Bulletin 15, 78-83. Neumaier A and Groeneveld E 1998. Restricted maximum likelihood estimation of covariances in sparse linear models. Genetics Selection Evolution 30, 3-26.

Nielsen US, Pedersen GA, Pedersen J and Jensen J 1999. Genetic variation in disease traits and their relationships with survival in Danish dairy cattle. Interbull Bulletin 21, 170-177.

Pérez-Guzmán MD 1984. Untersuchungen zur Melkbarkeit beim Rind 'Modellstudien und genetische Analyse'. Schriftenreihe des Institutes für Tierzucht und Tierhaltung der Christian-Albrechts-Universität zu Kiel, Bd. 20. Persson Waller K, Westermark T, Ekman T and Svennersten-Sjaunja K 2003. Milk leakage - an increased risk in automatic milking systems. Journal of Dairy Science 86, 3488-3497.

Pösö J and Mäntysaari EA 1996. Relationships between clinical mastitis, somatic cell score, and production for the first three lactations of Finnish Ayrshire. Journal of Dairy Science 79, 1284-1291.

Reinsch N 1996. Two Fortran programs for the Gibbs sampler in univariate linear mixed models. Archiv für Tierzucht 39, 203-209.

Rensing S 2005. New ways of data recording and genetic evaluation for functional traits. Proceedings of the 26th European Holstein and Red Holstein Conference, 18 to 22 May 2005, Prague, session 2.

Rensing S and Ruten W 2005. Genetic evaluation for milking speed in German Holstein population using different traits in a multiple trait repeatability model. Bulletin 33, Proceedings of the Interbull Meeting, Uppsala, Sweden.

Roth S, Reinsch N, Nieland G and Schallenberger E 1998. Untersuchungen über Zusammenhänge zwischen Eutergesundheit Melkbarkeitsparametern und Milchflußkurven an einer Hochleistungsrinderherde. Züchtungskunde 70, 242-260.

Rupp R and Boichard D 1999. Genetic parameters for clinical mastitis, somatic cell score, production, udder type traits and milking ease in first lactation cows. Journal of Dairy Science 82, 2198-2204.

Santus E and Bagnato A 1998. Genetic parameters estimation for milkability traits recorded with flowmeters in Italian Brown Swiss. Proceedings of the Sixth World Congress on Genetics Applied to Livestock Production, Australia 25, 19-22.

Sorensen DA, Andersen S, Gianola D and Korsgaard I 1995. Bayesian inference in threshold models using Gibbs sampling. Genetics Selection Evolution 27, 229-249.

Statistical Analysis Systems Institute 2000. User's guide (release 8.1.). Cary, NC, USA.

Trede J 1987. Genetische Analyse der Parameter der Eutergesundheit und der Melkbarkeit. Schriftenreihe des Institutes für Tierzucht und Tierhaltung der Christian-Albrechts-Universität zu Kiel, Bd. 44.

Vicario D, Degano L and Carnier P 2006. Genetic evaluation for milkability using subjective and measured observations in Italian dual purpose Simmental cows. Bulletin 35, Proceedings of the Interbull Meeting, Kuopio, Finland.

Zwald NR, Weigel KA, Chang YM, Welper RD and Clay JS 2005. Genetic evaluation of dairy sires for milking duration using electronically recorded milking times of their daughters. Journal of Dairy Science 88, 1192-1198.

Zwald NR, Weigel KA, Chang YM, Welper RD and Clay JS 2006. Genetic analysis of clinical mastitis data from on-farm management software using threshold models. Journal of Dairy Science 89, 330-336. 